\title{
INCIDENCIA DE INFECCIÓN POR Leptospira Sp. EN RONSOCOS (Hydrochoerus hydrochaeris) EN CAUTIVERIO EN UN ZOOCRIADERO DE IQUITOS
}

\author{
INCIDENCE OF INFECTION FOR LEPTOSPIRA SPP. IN CAPYBARAS (HYDROCHOERUS \\ hYdRochaeris) REAREd IN CAptivity IN IQUitos
}

Esther Cueva A. ${ }^{1}$, Hermelinda Rivera G. ${ }^{1,2}$, Nofre Sánchez P. ${ }^{3}$, Mercy Ramírez V. ${ }^{1}$

\section{RESUMEN}

\begin{abstract}
El objetivo del presente estudio fue determinar la incidencia de la infección de Leptospira sp. en ronsocos (Hydrochoerus hydrochaeris) de un zoocriadero en Iquitos. Se colectó muestras de sangre de 36 ronsocos adultos y juveniles de ambos sexos en tres muestreos con intervalo entre muestreos de dos meses, para la detección de anticuerpos contra 13 serovariedades de Leptospira sp. mediante la técnica de microaglutinación. Anticuerpos leptospirales fueron detectados en 97.2, 100 y $100 \%$ en el primer, segundo y tercer muestreo, respectivamente. Las serovariedades georgia, canicola y ballum fueron detectadas en los tres muestreos, pomona y australis en el segundo y tercer muestreo, mientras que tarassovi solo en el tercer muestreo. La serovariedad de mayor frecuencia fue georgia seguida por canicola y ballum. La incidencia acumulada con anticuerpos leptospirales fue $86.0 \pm 18.2 \%$ (31/36) de animales/0.25 año, que es la proporción de animales que se infectaron con Leptospira sp. en los cuatro meses de observación. La incidencia acumulada de georgia (100\%), ballum (36.3\%), canicola $(25.8 \%)$ y tarassovi $(16.6 \%)$ fueron las más importantes. Las muestras resultaron negativas a anticuerpos contra las serovariedades: icterohemorrhagiae, wolffi, hardjo, bratislava, grippotyphosa y javanica. Los resultados del presente estudio indican que la infección por Leptospira sp. es endémica en la población de ronsocos del zoocriadero en estudio.
\end{abstract}

Palabras clave: ronsoco, Hydrochoerus hydrochaeris, Leptospira sp., serovariedades, anticuerpos, incidencia

\section{Abstract}

The objective of this study was to determine the incidence of Leptospira sp., in capybaras (Hydrochoerus hydrochaeris) from a zoo farm in Iquitos, Loreto, Peru. Blood samples from 36 young and adults capyrabas, both female and male, were collected in

\footnotetext{
${ }^{1}$ Laboratorio de Microbiología y Parasitología Veterinaria, ${ }^{3}$ Estación Experimental del Centro de Investigación IVITA-Iquitos, Facultad de Medicina Veterinaria, Universidad Nacional Mayor de San Marcos, Lima

${ }^{2}$ E-mail: hriverag2005@yahoo.es
} 


\begin{abstract}
three samplings periods with a 2-month interval for detecting antibodies against 13 serovars of Leptospira sp. by microaglutination test. The $97.2,100$ y $100 \%$ of the samples collected during the first, second and third sampling period had antibodies against Leptospira sp. respectively. The serovar georgia, canicola and ballum were detected in the first, second and third sample, pomona and australis in the second and third, and tarassovi only in the third sampling period. The most frequent serovars were georgia, canicola, and ballum. The accumulated incidence of Leptospira sp. infection was $86.0 \pm$ $18.2 \%$ (31/36) animals/0.25year. The accumulated incidence of each serovar also indicated that georgia (100\%), ballum (36.3\%), canicola (25.8\%) and tarassovi $(16.6 \%)$ were the more frequent. The samples resulted negative to antibodies against the serovars icterohemorrhagiae, wolffi, hardjo, bratislava, grippotyphosa and javanica. The results indicate that Leptospira sp. infection is endemic on the capyraba population in the zoo farm in Iquitos city.
\end{abstract}

Key words: capybara, Hydrochoerus hydrochaeris, Leptospira sp., serovar, antibodies, incidence

\section{INTRODUCCIÓN}

El ronsoco (Hydrochoerus hydrochaeris) es el roedor más grande del mundo, y su hábitat se extiende desde Panamá hasta el norte de Argentina. Se le conoce, según el país de origen, como carpincho (Argentina), chigüiro o chigüire (Colombia), chigüiro (Venezuela), ronsoco (Perú) y capibara (Brasil). Es con este último nombre que es conocido a nivel mundial (FAO, 1987).

El ronsoco es una importante fuente de alimento para las poblaciones rurales de la región Amazónica (CONAM, 2005), así como fuente de ingresos económicos a través de la venta de cuero para exportación (INIA, 2004). Debido a su tamaño, productividad, rusticidad y buena adaptación al ecosistema de la sabana inundable, el ronsoco se le cría en forma semiextensiva en varios países de la región para la producción de carne y pieles (FAO, 1987). Su crianza ha sido promovida como fuente alternativa de recursos para el poblador amazónico y como una estrategia para su conservación; sin embargo, en el Perú, existen pocos zoocriaderos de ronsocos $y$, la gran mayoría de estos funcionan de manera clandestina (CONAM, 2005).
En general, las especies silvestres actúan como reservorio de diversas enfermedades y pueden ser fuentes de transmisión continua para poblaciones humanas y animales domésticos con los que comparten su hábitat (Acha y Szyfres, 2003). Asimismo, la introducción de especies silvestres a la zoocría incrementa el riesgo de transmisión de agentes infecciosos como la leptospirosis. Esta enfermedad, causada por la espiroqueta Leptospira sp. es una zoonosis reemergente de gran impacto en la salud pública. Su presencia está asociada a factores ecológicos que aseguran la supervivencia del patógeno en el medio ambiente, y donde las mayores prevalencias se presentan en regiones tropicales (Alonso et al., 2001; Levett, 2001; Bharti et al., 2003).

La Amazonía peruana presenta condiciones ambientales óptimas para el mantenimiento de Leptospiras en forma endémica. El contacto directo o indirecto de los animales domésticos con especies silvestres periurbanas, y el desarrollo urbano en zonas inundables con presencia de roedores completan los factores de riesgo identificados para esta región, donde se ha reportado prevalencias de leptospirosis humana y animal superiores a las observadas en la costa y 
sierra del país (Liceras y Mejia, 1982; Bharti et al., 2003; Mendoza, 2004; Céspedes et al., 2006).

Varias especies de fauna silvestre han sido identificadas como reservorios potenciales de Leptospira y se considera que pueden estar contribuyendo al mantenimiento y transmisión de la enfermedad (Bunnell et al., 2000; Muñoz et al., 2000; Mendoza, 2004). Estudios en la zona han determinado una alta prevalencia de Leptospira sp. en la población de animales silvestres (ronsocos y sajinos) criados en cautiverio, pero no se conoce su incidencia. El objetivo del presente estudio fue determinar la incidencia de la infección de Leptospira sp. en ronsocos $(H$. hydrochaeris) de un zoocriadero en la ciudad de Iquitos, en un contexto de vigilancia de esta enfermedad.

\section{Materiales y Métodos}

El presente estudio se realizó con animales de un zoocriadero ubicado dentro de la Reserva Nacional Allpahuayo - Mishana, en la carretera Iquitos - Nauta, cerca de la ciudad de Iquitos. La zona tiene una temperatura promedio de $25.9^{\circ} \mathrm{C}$ y una precipitación anual promedio de $2600 \mathrm{~mm}$.

Se muestrearon 36 ronsocos entre hembras $(\mathrm{n}=18)$ y machos $(\mathrm{n}=18)$. Los animales estaban considerados como adultos o juveniles, de apariencia normal, y se encontraban alojados en 30 ambientes de $42 \mathrm{~m}^{2} \mathrm{c} / \mathrm{u}$. Cada ambiente tiene un área para nado que constituye el $40 \%$ del corral, dispone de una zona con sombra y una tarima para protegerse del sol y las lluvias. Se realizó tres muestreos por animal en junio, agosto y octubre de 2006. Las muestras de sangre se obtuvieron por punción de la vena cefálica utilizando el sistema vacutainers. Los sueros resultantes se colocaron en crioviales y se trasladaron en congelación al Laboratorio de Microbiología y Parasitología Veterinaria de la Facultad de Medicina Veterinaria de la Uni- versidad Nacional Mayor de San Marcos, Lima, para la determinación de los anticuerpos contra Leptospira sp.

Los anticuerpos fueron detectados mediante la técnica de Aglutinación Microscópica (MAT), según el protocolo descrito por el Organismo Mundial de Sanidad Animal (antes OIE), utilizando una batería de 13 serovariedades o serovares de Leptospira sp. como antígeno vivo, evaluados previo a la realización de la prueba. Una muestra es considerada como positiva a anticuerpos leptospirales cuando es capaz de aglutinar igual o más del $50 \%$ de la Leptospira observado bajo un microscopio de campo oscuro y el título es la dilución más alta del suero que aglutina a $50 \%$ o más de la Leptopsira.

\section{Resultados}

El 97.2, 100 y $100 \%$ de los ronsocos fueron serorreactores a Leptospira sp. en el primer, segundo y tercer muestreo. Dentro de los animales reactores, el 19.4, 19.4, y $50 \%$ reaccionaron a más de un serovar en cada muestreo (Cuadro 1).

Todas las muestras resultaron negativas a anticuerpos contra $L$. pirogenes, $L$. icterohemorrhagiae, L. wolffi, L. hardjo, L. bratislava, L. grippotyphosa, L. javanica, pero no contra otros serovares (Cuadro 2). En los tres muestreos, el serovar más frecuente fue georgia, seguido de canicola y ballum.

La incidencia de la infección leptopiral fue $86 \pm 18.2 \%$ (31/36) de animales/0.25 año, que es la proporción de animales que se infectaron con Leptospira sp., en el periodo de 4 meses de observación. La incidencia acumulada de cada serovar varió de 5.5 a $100 \%$ de nuevos casos/0.25 año, siendo los más frecuentes georgia (100\%), seguido por ballum $(36.3 \%)$, canicola $(25.8 \%)$ y tarassovi (16.6\%) (Cuadro 3). 
Cuadro 1. Anticuerpos contra Leptospira sp. y títulos de anticuerpos detectados contra tres serovariedades en tres muestreos (junio, agosto y octubre de 2006) mediante la prueba de microaglutinación en 36 ronsocos en cautiverio en la zona de Iquitos

\begin{tabular}{|c|c|c|c|}
\hline Muestreo & $\begin{array}{c}\text { Reactores } \\
\mathrm{N}^{\circ} .(\%)\end{array}$ & Serovar detectado & Título de anticuerpos \\
\hline \multirow{5}{*}{ Primero } & $28(77.7)$ & georgia & $1 / 200$ \\
\hline & $4(11.1)$ & georgia-canicola & $1 / 100-1 / 100$ \\
\hline & $1(2.8)$ & georgia - canicola - ballum & $1 / 100-1 / 100-1 / 100$ \\
\hline & $2(5.5)$ & georgia-ballum & $1 / 100-1 / 100$ \\
\hline & $35(97.2)$ & & \\
\hline \multirow{6}{*}{ Segundo } & $29(80.5)$ & georgia & $1 / 400$ \\
\hline & $4(11.1)$ & georgia-ballun & $1 / 400-1 / 100$ \\
\hline & $1(2.8)$ & georgia - ballum-pomona & $1 / 400-1 / 100-1 / 100$ \\
\hline & $1(2.8)$ & georgia - ballum - canicola & $1 / 400-1 / 100-1 / 100$ \\
\hline & $1(2.8)$ & georgia - canicola-australis & $1 / 100-1 / 100-1 / 100$ \\
\hline & $36(100)$ & & \\
\hline \multirow{10}{*}{ Tercero } & $17(47.2)$ & georgia & $1 / 400$ \\
\hline & $4(11.1)$ & georgia - canicola & $1 / 400-1 / 100$ \\
\hline & $1(2.8)$ & georgia - canicola - tarassovi & $1 / 200-1 / 100-1 / 200$ \\
\hline & $1(2.8)$ & $\begin{array}{l}\text { georgia - canicola - ballum - } \\
\text { australis }\end{array}$ & $\begin{array}{l}1 / 400-1 / 100-1 / 100- \\
1 / 100\end{array}$ \\
\hline & $1(2.8)$ & georgia - pomona - tarassovi & $1 / 200-1 / 200-1 / 100$ \\
\hline & $7(19.4)$ & georgia-ballum & $1 / 400-1 / 200$ \\
\hline & $1(2.8)$ & georgia - ballum - tarassovi & $1 / 400-1 / 100$ \\
\hline & $3(8.3)$ & georgia-tarassovi & $1 / 200-1 / 200$ \\
\hline & $1(2.8)$ & canicola & $1 / 100$ \\
\hline & $36(100)$ & & \\
\hline
\end{tabular}

\section{Discusión}

Los resultados indican que Leptospira sp. es endémica en la población de ronsocos criados en cautiverio en el zoocriadero bajo estudio, con una frecuencia que varía entre 97.2 a $100 \%$ (Cuadro 1); especialmente por los serovares georgia, canicola y ballum (Cuadro 2). La alta frecuencia del serovar georgia, con títulos de anticuerpos no mayores a 1/400 sugiere que el ronsoco podría ser el reservorio de este serovar, ya que la Leptospira sp. no induce infección aguda ni altos títulos de anticuerpos pero el animal elimina la bacteria por la orina contaminando el medio ambiente (Bolin, 1998; Levett, 2001). Por otro lado, la infección suele ser aguda en animales que no son reservorios, desarrollando altos títulos de anticuerpos contra el serovar 
Cuadro 2. Frecuencia de anticuerpos contra los serovares de Leptospira sp. en tres muestreos (junio, agosto y octubre 2003) en la población de ronsocos de un zoocriadero de Iquitos

\begin{tabular}{cccc}
\hline \multirow{2}{*}{ Serovariedad de Leptospira } & \multicolumn{3}{c}{ Anticuerpos contra Leptospira sp. (\%) } \\
\cline { 2 - 4 } & Junio & Agosto & Octubre \\
\hline georgia & 97.2 & 100 & 97.2 \\
canicola & 13.9 & 5.6 & 19.4 \\
ballum & 8.3 & 16.7 & 25.0 \\
australis & 0 & 2.8 & 2.8 \\
pomona & 0 & 2.8 & 2.8 \\
tarassovi & 0 & 0 & 16.7 \\
\hline
\end{tabular}

Cuadro 3. Incidencia acumulada (\%) para cada serovariedad de Leptospira entre el primer y tercer muestreo (junio - octubre 2006) en la población de ronsocos de un zoocriadero de Iquitos

\begin{tabular}{lcc}
\hline Serovariedad & Nuevos positivos & $\begin{array}{c}\text { Incidencia acumulada por serovariedad/ } \\
\text { Incidencia acumulada total }\end{array}$ \\
\hline canicola & 8 & 25.8 \\
pomona & 2 & 5.5 \\
ballum & 12 & 36.3 \\
australis & 2 & 5.5 \\
georgia & 1 & 100.0 \\
tarassovi & 6 & 16.6 \\
\hline Total & 31 & 86.0 \\
\hline
\end{tabular}

infectante (Langoni et al., 1999). En un estudio previo en ronsocos de este zoocriadero no se obtuvo información sobre la presencia del serovar georgia en los ronsocos porque no fue incluido en la batería de antígeno (Muñoz et al., 2000); pero Mendoza (2004), en sajinos del mismo zoocriadero no detectó anticuerpos contra este serovar.
En el país existen escasos reportes de la alta prevalencia del serovar georgia. Mendoza (2004) reporta un seroreactor en sajinos de Pucallpa, aun cuando en Ucayali se ha reportado $31.3 \%(114 / 364)$ de personas con anticuerpos contra Leptospira sp.; donde los serovares más frecuentes fueron bratislava y georgia (Céspedes et al., 2006). Así mismo, se han detectado canes 
con signos de leptospirosis con altos títulos de anticuerpos contra el serovar georgia en Lima (H. Rivera, Lima, comunicación personal), indicando que este serovar está activo en la población de canes en la ciudad y, posiblemente, en el ambiente rural.

El $19.4 \%$ de la población de ronsocos presentó anticuerpos contra más de un serovar en los primeros dos muestreos y $50 \%$ en el tercer muestreo (Cuadro 1). La infección simultánea por distintos serovares es posible, ya que no existe protección cruzada entre los serovares, aunque en títulos de $1 /$ 100 o menos, puede observarse reacciones cruzadas inespecíficas; sin embargo, durante la convalescencia, los anticuerpos serovares específicos predominan en el animal (AwadMasalmeh y Willinger, 1982). Asimismo, la aparición de anticuerpos contra australis y pomona, a partir del segundo, y contra tarassovi, en el tercer muestreo (Cuadro 2), indica una dinámica de infección leptospiral o la introducción de nuevos individuos infectados al rebaño.

En el presente estudio, la incidencia acumulada de la infección fue de $86.0 \pm 18.2 \%$ (31/36) en 4 meses de observación (Cuadro 3) y la incidencia acumulada de cada serovar varió de 5.5 a $100 \%$ por cada 0.25 año. El resultado sugiere el alto riesgo de infección en poblaciones de ronsocos sometidas a condiciones de vida diferentes a las observadas en su medio natural (Suzán et al., 2000), pero también un alto riesgo de infección al hombre.

Es interesante la ausencia de anticuerpos contra el serovar icterohemorrhagiae ya que se reporta como reservorio a los roedores silvestres. Asimismo, la desaparición de anticuerpos en un periodo corto de dos meses, indica que la duración de la inmunidad contra Leptospira sp. en ronsocos es corta y el animal podría ser re-infectado por el mismo u otro serovar.

El medio ambiente y la presencia de los hospedadores de mantenimiento son reconocidos como los principales factores de riesgo de transmisión de la bacteria al hospedador accidental (hombre, otros mamíferos) (Bolín, 1998; Laguna, 2000). En la reserva Allpahuayo-Mishana, donde se ubica el zoocriadero en estudio, Bunell et al. (2000) identificaron varias especies de mamíferos silvestres, entre roedores, marsupiales y quirópteros, como reservorios potenciales de Leptospira sp., incluyendo ronsocos y sajinos (Muñoz et al., 2000; Mendoza, 2004).

Se concluye que existe una alta frecuencia de Leptospira sp. en ronsocos criados en cautiverio en la ciudad de Iquitos. Asimismo, el $86.0 \pm 18.2 \%$ de incidencia acumulada de infección leptospiral indica que la bacteria es endémica en la población de ronsocos estudiados.

\section{Literatura Citada}

1. Acha P, Szyfres B. 2003. Bacteriosis y micosis. En: Zoonosis y enfermedades transmisibles comunes al hombre y a los animales. Vol I. $3^{\text {a }}$ ed. Washington; OPS. $416 \mathrm{p}$.

2. Alonso C, García F, Ortega I. 2001. Epidemiología, diagnóstico y control de la leptospirosis bovina (Revisión). Invest Agro Prod Sanid Anim, España 16(2): 205-225.

3. Awad-Masalmeh A, Willinger $\boldsymbol{H}$. 1982. Evaluation of 2-mercapto-ethanol treatment in serodiagnosis of swine leptospirosis. Microbiologica 6: 133-143.

4. Bharti AR, Nally JE, Ricaldi JN, Matthias MA, Diaz MM, Lovett MA, Levett PN, et al. 2003. On behalf of the Peru - United States Leptospirosis Consortium. Leptospirosis: a zoonotic disease of global importance. Lancet Infec Dis 3: 757-771.

5. Bolin CA. 1998. Clinical signs, diagnosis and prevention of bovine leptospirosis. Bovine Practitioner 33(1): 50-55.

6. Bunnell JE, Hice CL, Watts DM, Montrueil V, Tesh RB, Vinetz JM. 2000. Detection of pathogenic Leptospira spp. infections among 
mammals captured in the Peruvian Amazon basin region. Am J Trop Med Hyg 63: 255- 258.

7. Céspedes M, Balda IJ, Gonzáles DQ, Tapia RI. 2006. Situación de la Leptospirosis en el Perú 1994 - 2004. Rev Perú Med Exp Salud Pública 23(1): 56-66.

8. [CONAM] Consejo Nacional del Ambiente. 2005. Indicadores ambientales Loreto - Perú. Serie Indicadores Ambientales 7. Lima: CONAM. 60 p.

9. [FAO] Food and Agriculture Organization of the United Nations. 1987. El capibara (Hydrochoerus hydrachaeris). Estado actual de su producción. [Internet], [5 octubre 2009]. Disponible en: http://www.fao.org/ DOCREP/004/v4590s/v4590509.htm

10. [INIA] Instituto Nacional de Investigación Agraria. 2004. Primer Informe Nacional Sobre la Situación de los Recursos. Mayo, 2004. [Internet], [20 noviembre 2007]. Disponible en: http:// www.inia.gob.pe/genetica/Zoogeneticos/ PINRZ\%20Peru\%20mayo\%202004a.pdf

11. Laguna V. 2000. Leptospirosis. Modulo técnico. Serie documentos monográficos $N^{\circ}$ 2. Lima: OGE-INS, Perú. 56 p.
12. Langoni H, de Souza IC, Vieira da Silva A, Luvizotto MC, Paes AC, Lucheis SB. 1999. Incidence of leptospiral abortion in Brazilian dairy cattle. Prev Vet Med 40: 271-275.

13. Levett PN. 2001. Leptospirosis. Clin Microbiol Reviews 14: 296-326.

14. Liceras J, Mejia E. 1982. Leptospirosis en Iquitos. Departamento de Loreto. Perú. Bol Oficina Sanit Panam 90(2): 152-158.

15. Mendoza AP. 2004. Presencia de anticuerpos contra leptospira sp. en Sajinos (Tayassu tajacu) mantenidos en cautiverio en la amazonia peruana. Tesis de Médico Veterinario. Lima: Universidad Nacional Mayor de San Marcos. 64 p.

16. Muñoz K, Cornejo C, Rivera H. 2000. Anticuerpos contra leptospira en capibaras (Hydrochoerus hydrochaeris) de un zoocriadero de la Amazonía Peruana. Rev Inv Vet, Perú 11(2): 167169.

17. Suzán G, Galindo F, Cevallos G. 2000. La importancia del estudio de enfermedades en la conservación de la fauna silvestre. Vet Mex 31: 223-230. 